\title{
A double-blind crossover comparison of Sinemet CR4 and standard Sinemet 25/100 in patients with Parkinson's disease and fluctuating motor performance
}

\author{
JESSE M CEDARBAUM, MARY HOEY, FLETCHER H MCDOWELL \\ From the Department of Neurology, Cornell University Medical College, The Burke Rehabilitation Center, \\ White Plains, and The New York Hospital, New York, NY, USA
}

SUMmary Fourteen Parkinsonian patients with fluctuations in therapeutic response to levodopa completed a double-blind, crossover trial of controlled-release levodopa/carbidopa (Sinemet CR4) vs standard Sinemet 25/100 (STD). Significant increases in mean interdose interval and per cent of the waking day spent "on", as well as reductions in the number of daily medication doses and number of "off" episodes were noted. In the double-blind part of the study, relative to open treatment with STD, ten patients rated themselves as improved while taking CR4, whereas only three considered themselves improved with STD. Difficulties using CR4 included an increased "lag-time" to the onset of antiparkinson effect, a tendency to produce increasingly severe dyskinesia late in the day, and a somewhat lessened predictability of motor response. Nonetheless, since the overall level of motor function through the day was equal to or better than that attained with STD, but with fewer medication administrations, Sinemet CR4 should prove a useful antiparkinsonian agent.

One of the major problems facing the physician treating patients with advanced Parkinson's disease with levodopa is the emergence of therapeutic response fluctuations (RFs).$^{1-3}$ RFs are, to a large extent, a pharmacokinetic phenomenon..$^{4-8}$ They result, at least in part, from the inability of the residual dopamine synthesis and storage capacity of the striatum of patients with advanced disease to "buffer" fluctuations in the availability of dopamine synthesised from exogenously administered levodopa, ${ }^{910}$ a drug with a short plasma half-life generally not exceeding 2 hours. ${ }^{10-12}$ Continuous intravenous infusions of levodopa have repeatedly been shown to reduce or eliminate RFs. ${ }^{81-17}$ Likewise, oral controlled-release formulations of levodopa plus decarboxylase inhibitor have been shown, in open studies, to reduce the frequency of "off" periods and to increase the interval at which medication doses are

Address for reprint requests: Dr Cedarbaum, The Burke Rehabilitation Center, 785 Mamaroneck Avenue, White Plains, NY 10605, USA.

This work was presented in part at the 112th meeting of the American Neurological Association, San Francisco, Ca, 18 October, 1987.

Received 17 May 1988 and in revised form 16 August 1988. Accepted 6 September 1988 required in Parkinson's disease patients with RFs. ${ }^{18-24}$ We now report the outcome of a double-blind, crossover comparison of one such preparation, Sinemet CR4, vs. standard Sinemet 25/100 (STD).

\section{Methods}

After giving informed consent, 19 patients entered and 14 completed the 24 week study. The mean age of the patients completing the study was 58.3, SEM 1.9 years; the mean duration of Parkinson's disease was 11.07, SEM 0.99 years, and the mean duration of RF was 3.78, SEM 0.66 years. All patients had idiopathic Parkinson's disease with disability scores when "off" of at least 2 (mean $=2 \cdot 86$, SEM 0.23) on the Hoehn and Yahr scale. All had an end-of-dose wearingoff pattern of RFs; all but two suffered peak-dose dyskinesia. Four additional patients had end-dose dystonia. Since it was considered preferable to compare formulations with identical carbidopa/levodopa ratios (Sinemet CR4 contains $50 \mathrm{mg}$ carbidopa and $200 \mathrm{mg}$ levodopa), those patients taking Sinemet $10 / 100$ or $25 / 250$ prior to study entry were switched to $25 / 100$ tablets, and the dose was adjusted to optimise performance before actual entry into the study. Six patients were taking anticholinergic agents and six amantadine at study entry (two were taking both). Three patients had been taking bromocriptine, which was discontinued at least 2 weeks prior to study entry.

The study consisted of two phases (fig 1): an 8-week open 


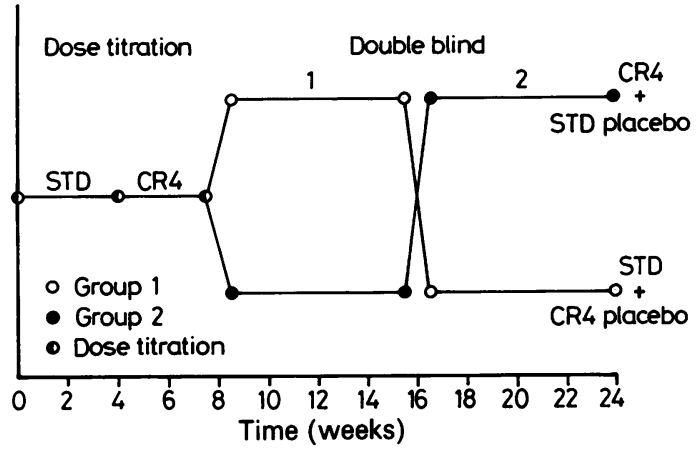

Fig 1 Diagram of the study design.

label dose-titration phase (DT) and a 16-week double-blind phase (DB). Each phase was likewise divided into two periods. During the first DT period (DT1), the dose of STD was adjusted to achieve maximum "on" time with as little "off" time and dyskinesia as possible. This process was repeated for CR4 during the second DT period (DT2). The starting interdose interval for the CR4 formulation was determined by doubling the final interdose interval from DT1. The initial dose was determined by taking the optimum 24-hour levodopa dose from DT1, and dividing by the number of doses to be taken. Fractional amounts were rounded upwards to compensate any decreased bioavailability of levodopa from CR4.

Following DT2, fourteen patients entered the DB phase. During this time, patients were given two sets of tablets, one resembling STD, and the other CR4. The patients were randomised into two groups. For one group, the yellow STD tablets contained placebo during the first DB period (DB1), during which they were given active CR4 tablets. Conversely, these patients received placebo CR4 tablets and active STD during DB2. For the remaining patients, the order was reversed, so that they received active CR4 tablets during DB2 and active STD during DB1. At the beginning of DB1, patients were instructed to take the yellow STD tablets on the same dose schedule as had been established during DT1, and the beige CR4 tablets on the schedule established at the end of DT2. If dose adjustments had to be made during the DB phase, the dose and/or interval for both tablets was adjusted concurrently.
At the end of each double-blind period, 8-hour observation studies were carried out as previously described. ${ }^{1920} Z$ Patients reported to the clinic before taking their first morning dose of medication, having eaten a low-protein $\&$ breakfast consisting of juice, toast and coffee. Patients who were too severely disabled to travel to the clinic in the morning without the benefit of medication, or who lived too far away were admitted to the hospital the evening prior to the study. From the time of the first dose, Parkinsonian disability and dyskinesias were rated at half-hourly or hourly intervals, utilising selected items from the modified Cornell- - . UCLA scoring system. An overall score, ranging from $-4 \overrightarrow{\overline{\bar{S}}}$ (most Parkinsonian) to +4 (violent dyskinesias), with zero $\stackrel{\oplus}{\rightarrow}$ representing the eumotoric state, ${ }^{25}$ was also assigned at each $\bar{C}$ time point. The patients were given a standard lunch, $\frac{\bar{O}}{\bar{F}}$ consisting of a fruit salad, clear soup, pie or cake and a $\frac{\bar{\omega}}{\bar{D}}$ beverage. Eight patients underwent similar studies at the end $\mathbb{\Phi}$ of each DT period, with blood samples taken for determination of plasma levodopa, 3-O-methyldopa (OMD) and $\omega$ carbidopa levels being drawn at the time of each examina- $\overrightarrow{0}$ tion. Two additional patients had blood level determinations performed during the DB observation studies. Plasma con- $\vec{\omega}$ centrations were determined using HPLC-ED, and will be reported in a separate communication. In no instance was information regarding plasma levodopa levels used to guide ? therapy in these patients.

The patients were evaluated biweekly, using the Unified is Parkinson Disease Scale (UPDS) ${ }^{26}$ and the Schwab an $\$$ England Activities of Daily Living (ADL) scale, according which patients (and/or spouses) were asked to rate overa⿱ ADL function as a percentage of normal $(100 \%=$ fulg independent, $0 \%=$ totally dependent in all $\mathrm{ADL}){ }^{27} \mathrm{ADE}$ using both the percent scale and ADL portions of the UPDS, $\mathbb{D}$ were rated by the patients and/or spouses for both the "oro and "off" conditions. In addition, patients kept diaries days each week, recording time spent "off," "on," and " with dyskinesias." At the end of each DB period, the patien $\overrightarrow{0}$ were asked to rate their performance as compared with DT1. At the end of DT2, patients were asked to express a preference for the drug taken during DB1 or DB2.

Data analysis was performed using the CLINFO computer facility of the Cornell Clinical Research Center. Compar- $\bar{\partial}$ isons were carried out using paired Student's $t$-tests and nonparametric statistics where appropriate.

Table 1 Dose information and tabulation of patient diaries

\begin{tabular}{|c|c|c|c|c|c|}
\hline \multirow{2}{*}{$\begin{array}{l}\text { Doses/day } \\
\text { Interval } \\
\text { MG dopa/day } \\
\text { \#"Offs"/day } \\
\% \text { "On" time total } \\
\text { With dyskinesia } \\
\text { "Lag time" (hr) } \\
\text { Improved vs STD } \\
\text { PTS preferring }\end{array}$} & \multicolumn{2}{|l|}{ Open-label } & \multicolumn{2}{|l|}{ Double-blind } & \multirow{2}{*}{$\begin{array}{l}\% \text { Change } \\
\text { (DB only) }\end{array}$} \\
\hline & $S T D(S E M)$ & $C R 4(S E M)$ & $S T D(S E M)$ & $C R 4(S E M)$ & \\
\hline
\end{tabular}

p Values (vs STD): $t$-test $\bullet<0.001 ; \S<0.002 ;$ ๆ $<0.0003 ; \ddagger<0.01 ; *<0.02 ; \#<0.05$

Chi-square: $\dagger=0.024 ; \|=0.0015$. 

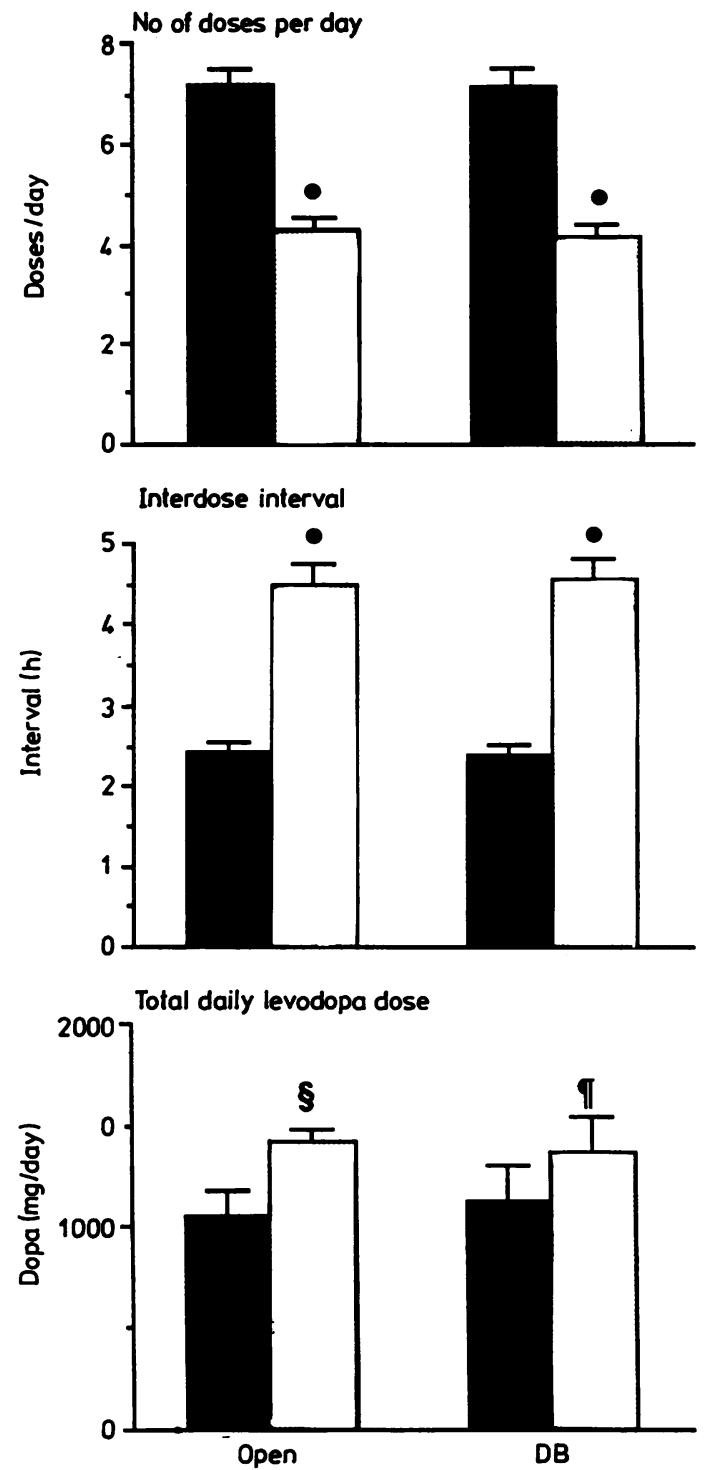

Fig 2 Number of daily medication doses (top), mean interdose interval (middle), and total daily levodopa dose (bottom) during both open label dose-titration ("OPEN") and double-blind ("DB") periods. $p<0.0001$; $\S p<0.0003 ;$ I $p<0.0005 ; C R 4$ (open bars) vs STD (filled bars).

\section{Results}

Dropouts: Five patients withdrew from the study, all during open-label treatment with CR4. One patient dropped out after 3 days of DT2 (CR4 dose titration) because he missed the "antiparkinson surge" of STD, and disliked the gradual onset of action of CR4. Four more patients dropped out at the end of DT2; two because of excessive dyskinesia, one due to worsened cognitive function, and one due to worsened Parkinsonism despite a marked increase in daily levodopa intake. The side-effect profile of CR4 was identical to that of STD. The patient who was dropped from the study due to worsened cognitive function had been moderately impaired prior to the study and continued to deteriorate thereafter.

In the double-blind portion of the study, 10 of the 14 patients considered their motor performance during the CR4 DB period to be better than it was during open-label treatment with STD during DT1, three patients considered themselves better when on STD in the DB phase than during DT1, and one could detect no difference (Chi-square $p=0.024$ ). In comparing performance during the two DB periods, 11 patients expressed a preference for the CR4 DB period, one for STD, and two had no preference (Chi-square $p=$ 0.0015). Eleven patients correctly surmised which tablet was the active one in each of the double blind periods, since individual doses of CR4 took longer to "kick in". This effect was evident even though patients with long delays to turn on were given a larger dose of CR4 upon arising in an attempt to have plasma levodopa levels reach "threshold" sooner. The remaining four patients could not distinguish between CR4 and STD.

During the DB periods of the study, the number of doses per day was $42 \%$ less for CR4 than for STD, $4 \cdot 14$, SEM 0.3 vs $7 \cdot 14$, SEM $0.3(\mathrm{p}<0.0001)$. The mean interdose interval was increased $86 \%$ from $2 \cdot 39$, SEM $0.1 \mathrm{~h}$ on STD to 4.57 , SEM 0.2 on CR4 (p < 0.0001 ). However, the mean daily intake of levodopa was increased $21.8 \%$, from 1128.6 , SEM 117.5 to $1371 \cdot 4$, SEM $172.1 \mathrm{mg} /$ day ( $\mathrm{p}<0.0003$ ). A substantial part of this increase may have been due to the fact that patients were given a bedtime dose of CR4 in hopes of extending benefit into the night. However, only two patients specifically commented on improved sleep patterns or ease of getting out of bed at night,

Table 2 Subjective patient ratings of $A D L$ function

\begin{tabular}{|c|c|c|c|c|}
\hline & \multicolumn{2}{|l|}{ Open-label } & \multicolumn{2}{|l|}{ Double-blind } \\
\hline & $\begin{array}{l}S T D \\
\quad(S E M)\end{array}$ & $\begin{array}{l}C R 4 \\
\quad(S E M)\end{array}$ & $\begin{array}{l}S T D \\
\quad(S E M)\end{array}$ & $\begin{array}{l}C R 4 \\
\quad(S E M)\end{array}$ \\
\hline $\begin{array}{c}\text { Schwab \& E } \\
\text { "On" } \\
\text { "Off" } \\
\Delta \text { Off-On }\end{array}$ & $\begin{array}{l}\text { ngland (perce } \\
84 \cdot 28(3.43) \\
57 \cdot 14(4 \cdot 24) \\
27 \cdot 14(3.39)\end{array}$ & $\begin{array}{l}\text { nt of "normal") } \\
86.42(2 \cdot 69) \\
65.00(4 \cdot 16)^{*} \\
21.42(3 \cdot 29)\end{array}$ & $\begin{array}{l}83.60(3.07) \\
53.57(4.87) \\
30.00(3.78)\end{array}$ & $\begin{array}{l}84 \cdot 29(3 \cdot 26) \\
57 \cdot 14(5 \cdot 07) \\
27 \cdot 14(3 \cdot 10)\end{array}$ \\
\hline $\begin{array}{c}\text { UPDS ADI } \\
\text { "On" } \\
\text { "Off" } \\
\Delta \text { Off-On }\end{array}$ & $\begin{array}{c}\text { self-rating: } \\
2.57(0.82) \\
13.36(1.47) \\
10.79(0.87)\end{array}$ & $\begin{array}{r}2.86(1.04) \\
12.14(1.33) \\
9.29(1.21)\end{array}$ & $\begin{array}{r}3.43(1.19) \\
13.07(1.94) \\
9.64(1.58)\end{array}$ & $\begin{array}{r}3.57(1.55) \\
13.36(1.99) \\
9.79(1.59)\end{array}$ \\
\hline
\end{tabular}

$\mathrm{p}$ Values $*<0.05 . \Delta=$ On-Off difference. 

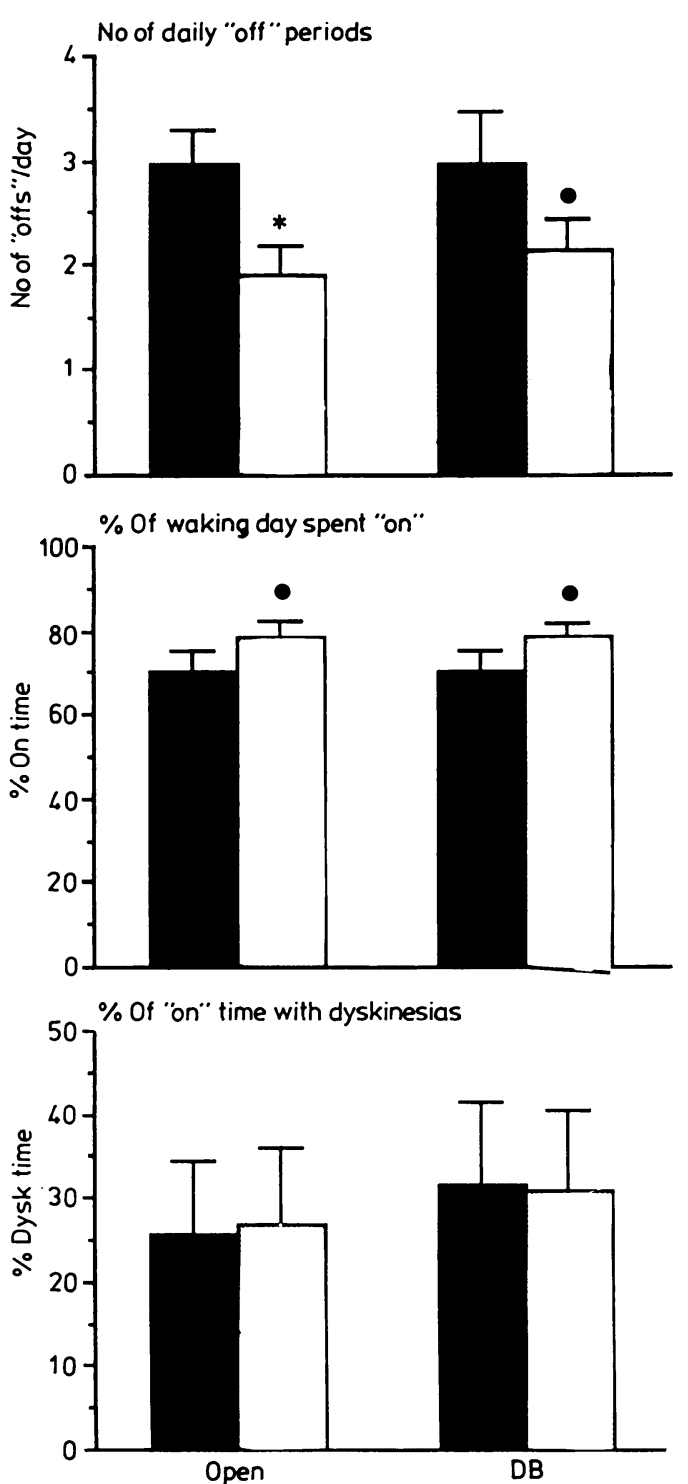

Fig 3 Number of "off" periods per day (top), per cent of the waking day spent "on" (middle), and per cent of "on" time occupied with dyskinesias during both open label dosetitration ("OPEN") and double-blind ("DB") periods. - $p<0.02 ;{ }^{*} p<0.0001, C R 4$ (open bars) vs STD (filled bars).

and the mean initial Parkinson disability scores on the days of serial clinical observations were not different for the two formulations, indicating that medication given at bedtime failed to last through the entire night. There were no significant differences between the DB and DT periods for either STD or CR4 in the number of doses per day, the mean interdose interval or in total
Table 3 Results of 8-hour observation studies (double-blind $\mathbf{Z}$ periods only)

\begin{tabular}{|c|c|c|}
\hline & $S T D(S E M)$ & $C R 4(S E M)$ \\
\hline \multicolumn{3}{|c|}{ Modified Cornell PD score: } \\
\hline Mean & $41.44 \quad(4.77)$ & $39 \cdot 33 \quad(7 \cdot 23)$ \\
\hline Range & $55.36 \quad(8.06)$ & $51 \cdot 50 \quad(5 \cdot 98)$ \\
\hline $\mathrm{CV}$ & $55.81 \quad(9.66)$ & $61 \cdot 16(9 \cdot 7)$ \\
\hline AUC & $310 \cdot 32(49 \cdot 46)$ & $289 \cdot 36(56 \cdot 87)$ \\
\hline \multicolumn{3}{|c|}{ "Global" rating: } \\
\hline Mean & $-0.04(0.19)$ & $-0.07 \quad(0 \cdot 21)$ \\
\hline Range & $3.07 \quad(0.28)$ & $2.50 \quad(0.27)$ \\
\hline $\mathrm{CV}$ & $208.94(43.42)$ & $263 \cdot 11(52 \cdot 65)$ \\
\hline AUC & $1.32(1.54)$ & $0.59(1.71)$ \\
\hline Lag time & $0.96 \quad(0.18)$ & $1.82(0.33)^{x}$ \\
\hline \multicolumn{3}{|c|}{ Dyskinesia score: } \\
\hline Mean & $2.57 \quad(0.56)$ & $2 \cdot 14 \quad(0 \cdot 44)$ \\
\hline Range & $4.89(1.19)$ & $5.54(1.01)$ \\
\hline $\mathrm{CV}$ & $61 \cdot 22(16 \cdot 1)$ & $152.58(29.4)^{\dagger}$ \\
\hline AUC & $21.88(5.34)$ & $18.72(3.40)$ \\
\hline
\end{tabular}

p Values $*<0.02 ; \dagger<0.05$.
AUC, area under curve; CV, coefficient of variation (Std $\overrightarrow{\vec{\omega}}$ Dev/Mean).

daily levodopa intake (table 1 and fig 2). Neither the number of or interval between STD doses during DT 1 N predicted the final dose or interval for CR4 treatment in but most patients easily tolerated a doubling of the्pir previous interdose interval up to a maximum of hours.

During the DB phase of the study, there was $28.6 \%$ reduction in the number of daily "off " periods, $\frac{D}{\square}$ from 2.97 , SEM 0.5 on STD to $2 \cdot 12$, SEM 0.3 on C $(\mathrm{p}<0.02)$, and a $11.6 \%$ increase in the percent of the waking day spent "on", from $70 \cdot 12$, SEM $5 \cdot 0$ to $78 \cdot \overrightarrow{0}$ SEM $3.6 \%(p<0.02)$. The percentage of "on" time spent with dyskinesia was unchanged. Again these. results were not significantly different from thoseo obtained during the DT periods (table 1 and fig 3). Curiously, review of patients' diaries from the last $4 \overline{0}$ weeks of each double blind period did not support $\frac{0}{8}$ patients' observations of an increased "lag time" with $\stackrel{\mathbb{Q}}{2}$ CR4. The mean interval recorded from the time of the $\overrightarrow{\overrightarrow{0}}$ first dose of medication in the morning to the time 3 when patients first reported being "on" was $0 \cdot 96$, SEM 0.28 (median 0.61 ) hours on STD and 0.96 , SEM $0 \cdot 19$ 우․ (median $1 \cdot 125$ ) hours on CR.

The quantitative improvement in RFs was not, however, accompanied by a qualitative improvement. 0 Except for a slight improvement on "off" period selfrating during the open-label portion of the study, 8 mean ADL self-ratings revealed no difference in best $₹$ "on" performance, worst "off" performance, or in the difference between them ( $\Delta$ Off-On) on either the UPDS or the percent scales (table 2). These self-O observations were confirmed by the lack of significant difference in the mean, range, coefficient of variation. $(\mathrm{C} . \mathrm{V} .=\mathrm{Std} \operatorname{Dev} /$ Mean), or the area under the N disability score-vs-time curve of Parkinson disability N 
or global rating scores obtained during the serial observation studies (table 3). However, in contrast to patients' diary reports, an increased "lag time" to the onset of medication effect was reflected by an increase in the interval between the first dose and the first recorded "global" score of 0 or greater, being 0.96 , SEM 0.18 (median 0.75) hours on STD and 1.82, SEM 0.33 (median 1.5) hours on CR4.

\section{Discussion}

The patients completing this double-blind, placebocontrolled, crossover study preferred Sinemet CR4 to STD by a ratio of 3:1. If the patients who dropped out due to excessive dyskinesia or lack of drug effect during the DT phase are included, $58 \%$ of the study entrants perceived benefit from CR4 (Chi-square $p=$ 0.04). Patients completing the double-blind portion of the study achieved a slight increase in the amount of daily "on" time when on CR4 as well as a $28.6 \%$ reduction in the number of "off" episodes, while taking $42 \%$ fewer doses of medication per day than when they were taking STD.

No differences were noted between DT and DB periods for either formulation, and the majority of patients correctly identified the active formulation during the "blinded" periods of the study. This suggests that the blind was, in fact, not adequately maintained owing to the quite distinct temporal pattern of clinical response to CR4 and STD. In fact, complete masking of a study comparing these two formulations may well be impossible for this reason. Nevertheless, the results of this study confirm the results of our previous open-label study with CR4 ${ }^{2021}$ as well as those of Goetz et al. ${ }^{23}$ Similar results were also obtained by Sage and Mark in a study of similar design to our own. ${ }^{28}$ These investigators reported an increase of "on" time in $58 \%$ of patients, with $79 \%$ of patients taking fewer doses per day of CR than of STD, and a reduction in the mean number of doses taken per day from 7.8 of STD to $5 \cdot 3$ of CR4.

Sinemet CR4 behaves more as a slow-release than a truly controlled-release preparation. ${ }^{20}$ Absorption of levodopa from CR4 does not provide constant plasma levodopa levels throughout the day, but rather allows for an extended interdose interval by prolonging the absorptive phase of the dose cycle. The slower absorption of levodopa from CR4 has two major consequences. The first is an increased lag time to the onset of action of individual doses. This was experienced by the patients as a delay to turn "on" in the morning following the first dose of the day, and some patients disliked the absence of a "surge" of energy at the onset of medication, an effect they were accustomed to with STD. The action of successive doses during the day also tended to be less reliable than with STD, and occasional long delays to turn "on", as well as a decreased predictability in the occurrence of "off" periods, were experienced by most patients. The second major consequence of the prolonged absorption of levodopa from CR4 is that successive doses tend to produce successively greater peaks in plasma levodopa levels, since interdose trough levels tend to be higher than those seen with STD. This led to increasing severity of dyskinesia late in the day, which was dealt with by giving larger doses in the morning than in the afternoon. Reducing the size of the afternoon doses often reduced the amount of dyskinesia, but at the price of additional "off" time. In open treatment we have found the addition of STD to CR4, particularly at the first morning dose and as a prn medication during the day, ${ }^{20}{ }^{21}$ can effectively compensate for the increased lag time of CR4 and, in fact, the two are best used in combination.

As in the above-mentioned studies, ${ }^{21-2328}$ there was no improvement reported by the patients in the quality of their "on" time during CR4 treatment. That the quality of the "on" time experienced was no different from that with STD should not be surprising. Nutt $e t$ al have demonstrated a "ceiling" effect in the action of levodopa. That is, that increasing the dose beyond a certain level for a given patient produces increments only in the duration, but not the quality of the antiparkinson effect, whereas the severity of dyskinesia continues to increase.

Given the limitations inherent in the pharmacokinetics and pharmacodynamics of levodopa, Sinemet CR4 appears to be a useful addition to our therapeutic armamentarium. In our group of patients with predictable end-of-dose wearing-off of levodopa effect and relatively mild dyskinesia, reduced dosing frequency and the consequent reduction in the number of "off" periods per day were universally cited by all patients and spouses alike as the major benefit of CR4. It is in this type of patient that CR4 is likely to find its greatest usefulness. However, patient with more complicated patterns of response fluctuations may benefit as well. ${ }^{20}$

We thank the nursing staffs of the Burke Rehabilitation Center and the Payson 2 Clinical Research Center of the New York Hospital. Ms Amy Harts assisted in data collection and analysis. This work was supported in part by the Winifred Masterson Burke Relief Foundation; the G Harold and Leila Y Mathers Charitable Foundation; the Shirley Winkler Parkinson Research Fund of the Burke Rehabilitation Center; PHS research grant RR0047 from the Division of Research Resources, NIH; and Merck, Sharp \& Dohme, Inc.

\section{References}

1 Cedarbaum JM, McDowell FH. Sixteen-year follow-up of patients begun on levodopa in 1968: emerging problems. $A d v$ Neurol 1986;5:469-72. 
2 Fahn S. Fluctuations of disability in Parkinson's disease: pathophysiology. In: Marsden CD, Fahn S, eds. Movement Disorders. Boston: Butterworth Scientific, 1982:123-45.

3 Marsden CD, Parkes JD, Quinn N. Fluctuations of disability in Parkinson's disease: clinical aspects. In: Marsden CD, Fahn S, eds. Movement Disorders. Boston: Butterworth Scientific, 1982: 96-122.

4 Muenter MD, Tyce GM. I-Dopa therapy of Parkinson's disease: plasma 1-dopa concentration, therapeutic response and side effects. Mayo Clin Proc 1971;46:123-39.

5 Sweet RD, McDowell FH. Plasma dopa concentrations and the "on-off" effect after chronic treatment of Parkinson's disease. Neurology 1984;24:953-6.

6 Tolosa ES, Martin WE, Cohen HP, Jacobson RL. Pattern of clinical response and plasma dopa levels in Parkinson's disease. Neurology 1975;25:177-83.

7 Nutt JG, Woodward WR. Levodopa pharmacokinetics and pharmacodynamics in fluctuating Parkinsonian patients. Neurology 1986;36:1206-11.

8 Shoulson I, Glaubiger GA, Chase TN. "On-off" response: clinical and biochemical correlations during oral and intravenous levodopa administration in Parkinsonian patients. Neurology 1975;25:1144-8.

9 Spencer SE, Wooten GF. Altered pharmacokinetics of l-dopa metabolism in rat striatum deprived of dopaminergic innervation. Neurology 1984;34:1105-8.

10 Fabbrini G, Juncos J, Mouradian M, Serrati C, Chase TN. Levodopa pharmacokinetics and motor fluctuations in Parkinson's disease. Ann Neurol 1987;27:372-6.

11 Nutt JG, Woodward WR, Anderson JL. The effect of carbidopa on the pharmacokinetics of intravenously administered levodopa; the mechanism of action in the treatment of Parkinsonism. Ann Neurol 1985;18:537-43.

12 Hardie RJ, Malcom SL, Lees AJ, Stern GM, Allen JG. The pharmacokinetics of intravenous and oral levodopa in patients with Parkinson's disease who exhibit on-off fluctuations. Br J Clin Pharmacol 1986;22:429-36.

13 Hardie RJ, Lees AJ, Stern GM. On-off fluctuations in Parkinson's disease. Brain 1984;107:487-506.

14 Quinn NP, Parkes JD, Marsden CD. Control of on/off phenomenon by continuous infusion of levodopa. Neurology 1984;34:1131-6.

15 Marion MH, Stocci F, Quinn NP, Jenner P, Marsden CD. Repeated levodopa infusions in fluctuating Parkinson's disease: clinical and pharmacokinetic data. Clin Neurophamacol 1986;
9:165-81.

16 Mouradian MM, Juncos JG, Fabbrini G, Chase TN. Motor fluctuations in Parkinson's disease: pathogenetic and therapeutic studies. Ann Neurol 1987;22:475-9.

17 Juncos J, Serrati C, Fabbrini G, Chase TN. Fluctuating levodopa concentrations and Parkinson's disease. Lancet 1985;ii:440.

18 Nutt JG, Woodward WR, Carter JH. Clinical and biochemical studies with controlled-release levodopa/carbidopa. Neurology 1986;36:1206-11.

19 Cedarbaum JM, Breck L, Kutt H, McDowell FH. Controlledrelease levodopa/carbidopa I. Sinemet CR3 treatment of response fluctuations in Parkinson's disease. Neurology 1987; 37:233-41.

20 Cedarbaum JM, Breck L, Kutt H, McDowell FH. Controlledrelease levodopa/carbidopa II. Sinemet CR4 treatment of response fluctuations in Parkinson's disease. Neurology 1987; 37:1607-12.

21 Cedarbaum JM, Hoey M, Kutt H, McDowell FH. Results of longterm treatment with controlled-release levodopa/carbidopa (Sinemet CR4). Ann Neurol 1987;22:145.

22 Cedarbaum JM, Hoey M, Kutt H, McDowell FH. Controlledrelease levodopa/carbidopa III. Sinemet CR5 treatment of response fluctuations in Parkinson's disease. Clin Neurophamacol 1988;11:168-73.

23 Goetz CG, Tanner CM, Klawans HC, Shannon KM, Caroll VS. Parkinson's disease and motor fluctuations: long-acting carbidopa/levodopa (CR4-Sinemet). Neurology 1987;37:875-8.

24 Poewe WH, Lees AJ, Stern GM. Treatment of motor fluctuations in Parkinson's disease with an oral sustained-release preparation of L-dopa: clinical and pharmacokinetic observations. Clin Neurophamacol 1986;9:430-39.

25 Fahn S. "On-off" phenomenon with levodopa therapy in Parkin sonism. Neurology 1974;24:431-44.

26 Fahn S, Elton RL, et al. Unified Parkinson's Disease Rating Scale In: Fahn S, et al, eds. Recent Developments in Parkinson Disease, vol 2. New Jersey: Macmillan Healthcare Information 1987:153-63.

27 Schwab RS, England AC. Projection technique for evaluating surgery in Parkinson's disease. In: Gillingham FJ, Donaldsom IML, eds. Third Symposium on Parkinson's disease. Edinburghr E \& S Livingstone, 1969:152-7.

28 Sage JI, Mark MH. Comparison of controlled-release Sinemet (CR4) and standard Sinemet $(25 \mathrm{mg} / 100 \mathrm{mg})$ in advanced Parkinson's disease: a double-blind, crossover study. Clin Neurophamacol 1988;11:174-9. 